\title{
Leibniz and the Foundations of Physics: The Later Years
}

\section{Citation}

McDonough, Jeffrey K. 2016. Leibniz and the Foundations of Physics: The Later Years.

Philosophical Review 125, no. 1: 1-34. doi:10.1215/00318108-3321711.

\section{Published Version}

doi:10.1215/00318108-3321711

\section{Permanent link}

http://nrs.harvard.edu/urn-3:HUL.InstRepos:30780190

\section{Terms of Use}

This article was downloaded from Harvard University's DASH repository, and is made available under the terms and conditions applicable to Open Access Policy Articles, as set forth at http:// nrs.harvard.edu/urn-3:HUL.InstRepos:dash.current.terms-of-use\#OAP

\section{Share Your Story}

The Harvard community has made this article openly available.

Please share how this access benefits you. Submit a story.

Accessibility 


\title{
Leibniz and the Foundations of Physics: The Later Years
}

\author{
Jeffrey K. McDonough
}

\section{Introduction}

In the opening paragraphs of his now classic paper "Leibniz and the Foundations of Physics: The Middle Years," Daniel Garber suggests that Leibniz must seem something of a paradox to contemporary readers $(1985,27)$. On the one hand, Leibniz is commonly held to have advanced a broadly idealist metaphysics according to which the world is ultimately grounded in mind-like monads whose properties are exhausted by their perceptions and appetites. On such a picture, physical bodies would seem to be nothing more than the perceptions or thoughts (or contents thereof) enjoyed by immaterial substances. ${ }^{1}$ On the other hand, it is generally recognized (if perhaps less clearly) that Leibniz was also a prominent physicist in his own day and that he saw his work in physics as supporting, and being supported by, his metaphysics. ${ }^{2}$ But how, in light of his idealism, could that be? How could Leibniz think that his pioneering work in physics might lend support to his idealist metaphysics, and conversely that his

Earlier versions of this essay were presented to audiences at the Westfälische Wilhelms-Universität Münster, Yale University, Brown University, and Dartmouth College. I am grateful to participants at those events as well as to referees of this journal for their comments on earlier drafts. I owe special thanks as well to Donald Rutherford and Samuel Levey for helpful discussion of the material presented here.

${ }^{1}$ For an entry point into idealist interpretations of Leibniz's metaphysics, see Adams (1994) and Rutherford (1995).

${ }^{2}$ For an entry point into Leibniz's physics, see Garber (1995), Hecht (1992), and McDonough (2014). 
idealist metaphysics might provide an especially intelligible foundation for his sophisticated physics?

A familiar story suggests that Leibniz effectively develops two separate systems, bridged by divine benevolence. ${ }^{3}$ On this account, physics is a science of appearances, metaphysics a science of reality, and God's goodness assures us that our investigations of the former will somehow provide insight into the latter. Resisting this traditional story as a complete account, Garber boldly proposed that for much of his career Leibniz could see a more intimate connection between his physics and his metaphysics. Garber argued that during his "middle years" Leibniz subscribed not to a broadly idealist metaphysics of unextended, immaterial substances, but rather to a realist metaphysics of extended, corporeal substances. During that period, he claimed, Leibniz could take the objects of his physics to be literally constituted by the objects of his fundamental metaphysics, much as we commonly take, say, the objects of biology to be constituted by the objects of chemistry. On Garber's interpretation, Leibniz, for at least much of his career, could see his studies in physics as being continuous with his studies in metaphysics just as we are inclined to see biology as being continuous with chemistry. Garber suggested that, at least during his middle years, Leibniz appears first and foremost as a natural philosopher, a systematic thinker who takes for granted an intimate connection between his physics and his metaphysics precisely because he recognizes no principled distinction between his work qua physicist and his work qua metaphysician.

Garber's groundbreaking proposal for understanding Leibniz's attitude toward the foundations of physics quickly sparked controversy concerning Leibniz's commitment to corporeal substances. ${ }^{4}$ In the intense debate that ensued, however, Garber's original paradox, as well as the obvious limitation of his solution to it, largely fell out of focus. Although Leibniz's views on corporeal substances remain controversial, almost all commentators, including Garber, agree that at some point Leibniz's metaphysics turns recognizably monadic (see Garber 1985, 99; 2009, 303388). And after that point - whenever that point might be - Garber's original paradox must reemerge in full force. For as soon as the deepest foundations of Leibniz's metaphysics are exhausted not by extended,

${ }^{3}$ For sophisticated developments of this story, see Adams (1994, 217-399), Gueroult (1967, 210-214), and Rutherford (1995, 177-288).

${ }^{4}$ For a helpful overview of the debate and further references, see Levey (2011).

"Leibniz and the Foundations of Physics: The Later Years," to appear in 
material substances, but rather unextended, immaterial monads, it becomes unclear, once again, how he could see his pioneering physics as lending support to his idealist metaphysics and his idealist metaphysics as providing an especially intelligible foundation for his sophisticated physics. In short, even if corporeal substances can help us make sense of Leibniz's attitude towards the foundations of physics in his "middle years," we still face the challenge of making sense of his attitude towards the foundations of physics in what we might correlatively call his "later years."

The following essay takes up that challenge by offering an account of the relationship between extended Leibnizian bodies and unextended Leibnizian monads, an account that shows why Leibniz was right to see intimate, explanatory connections between his studies in physics and his mature metaphysics. The first section sets the stage by introducing an especially relevant case study from Leibniz's technical work in natural philosophy, namely, his historically important, but almost wholly neglected, investigation of the strength of extended, rigid beams. The second section draws on that case study to introduce a model for understanding Leibniz's views on the relationship between the derivative and primitive forces. The third section draws on Leibniz's understanding of the relationship between derivative and primitive forces in order to shed light in turn on his understanding of the relationship between the extended, material bodies and unextended, immaterial monads. The fourth section responds to a likely objection by arguing that Leibniz's monads may, in a perfectly reasonable sense, be spatially located.

\section{Leibniz on Rigid Beams}

Galileo initiated the mathematical study of elasticity in general, and the strength of rigid bodies in particular, with the second day of his Two New Sciences (1890-1910, 8:151-190/1974, 109-146). There Galileo introduces the following problem: if a prismatic beam is set into a wall at one end, and loaded with a weight at the other end, how much weight is needed in order to break the beam? Making reference to Figure 1, Galileo suggests that the beam should be thought of as a two-armed lever with a fulcrum at B (1890-1910, 8:156/1974, 115). The beam can then be thought of as being attached to the wall along the arm $\mathrm{BA}$, and the weight $\mathrm{E}$ can be thought of as applying a downward force on the arm BC. 


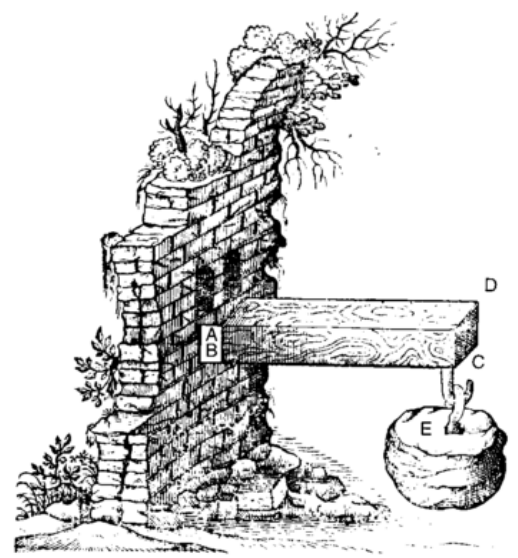

Figure 1

Galileo's calculation of how much weight the beam can support is presented as a ratio comparing the amount of force it would take to break the beam by pulling directly on it along the horizontal direction and the amount of force it would take to break the beam by applying a downward force at the end of the beam. Letting $P_{t}=$ the force required to break the beam by direct pulling (where " $\mathrm{t}$ " stands for "tension") and $\mathrm{P}_{\mathrm{b}}=$ the force required to break the beam by applying a force at point $\mathrm{C}$, Galileo argues that $\mathrm{P}_{\mathrm{b}}=1 / 2 \mathrm{P}_{\mathrm{t}} .^{5}$

Leibniz begins his discussion in his Demonstrationes Novae (1684) by acknowledging a debt to Galileo, who, as he puts it, "equipped with a discerning judgment and a strong grasp of the geometry of interiors, first ... began to relate the resistance of solids to geometrical laws" $(1684,319)$. Nonetheless, Leibniz notes that experimental results, especially those conducted by Marriotte, with whom Leibniz was in direct correspondence, suggest "a much lesser weight $F$ is sufficient to break the beam than Galileo wanted." The root of Galileo's error, Leibniz argues, is that "he considered a perfectly rigid beam, which would be broken off at a single instant once its resistance has become excessive" $(1684,321)$. Leibniz maintains, on the contrary, however, that all beams "yield to some extent before they can be torn off ... [as] can be seen by the example of a staff which twists before it shatters, and the example of strings, which stretch out before they break" $(1684,321)$. Taking into account variations in resistance over the cross-

${ }^{5}$ For discussion of Galileo's treatment of rigid beams, see Truesdell (1957, 34-44) and Benvenuto (1991, 176-197). 
sections of a beam as well as over its length, Leibniz arrives at an improved formula for a cubic beam, namely, $\mathrm{P}_{\mathrm{b}}=1 / 3 \mathrm{P}_{\mathrm{t}} \cdot{ }^{6}$

In order to arrive at this result, and to take into account the flexibility of weighted beams, Leibniz imagines a representative beam as first being composed along the horizontal dimension by long "fibers" running from end to end, and, second, by vertical "slices" or "elements." In this way, the beam is to be imagined as a series of discrete blocks that are strung-through by horizontal fibers so that each fiber runs through every element and each element contains a cross section of all the horizontal fibers, as in Figure 2 (not due to Leibniz):

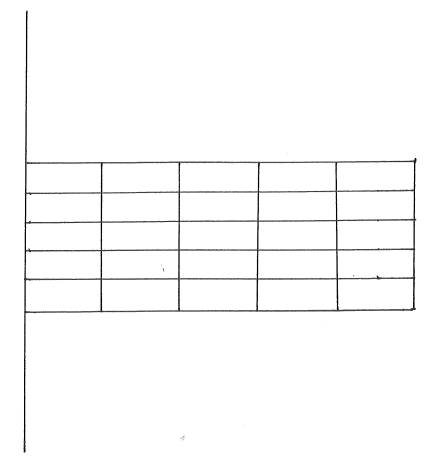

Figure 2

It is worth noting that Leibniz's division of the beam into fibers and elements is in a way arbitrary and in a way not arbitrary. As is well known, Leibniz believes that all gross bodies are actually, infinitely divided. His division of the beam into threads and elements, however, is not meant to correspond directly to the divisions that he thinks must actually be present in the beam. The highly idealized division of the beam in to threads and elements is thus, in one way, clearly and intentionally arbitrary. As Mark Wilson has recently emphasized, however, we all know from everyday experience that weighted beams distort primarily along two dimensions, the vertical and the horizontal. Leibniz's idealized division of the beam cleverly exploits this experiential knowledge by bringing to the fore the two dimensions that will require the closest scrutiny if a workable equation for rigid beams is to be produced. It is thus, in another way, anything but arbitrary (Wilson 2010, 2).

${ }^{6}$ For discussion of Leibniz's treatment of rigid beams, see Truesdell (1957, 59-64), Hecht (1992, 100-112) and Wilson (2010). 
Having divided the beam into idealized fibers and elements, Leibniz next imagines that the fibers act like springs holding the elements together so that the beam may be thought of as a series of rigid blocks connected by springs strung between the connecting surfaces. Figure 3 represents one such block $\mathrm{ABKC}$, which itself functions as a two-armed lever with a fulcrum at $\mathrm{A}$ connected to the neighboring surface $\mathrm{DE}$ by springs such as $1 \mathrm{~B} 2 \mathrm{~B}$ and $1 \mathrm{H} 2 \mathrm{H}$, and weighted at $\mathrm{C}$ along the arm $\mathrm{AC}$.

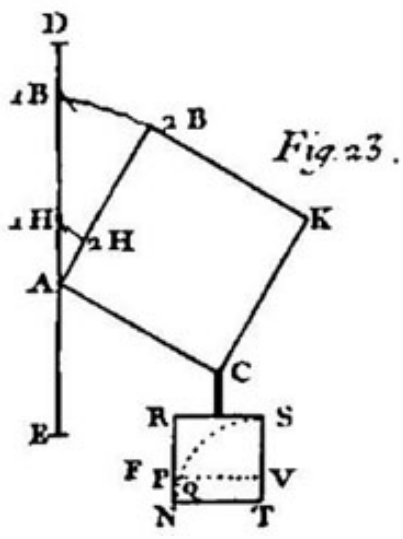

Figure 3

Attention to Figure 3 highlights in an especially clear way that Leibniz's division of the beam into threads and elements is not just idealized but - by his own lights - patently artificial. For, first of all, each element is conceived as a perfectly inflexible, rigid block. But, as we've just seen, Leibniz thinks that there are no perfectly inflexible, rigid blocks, and, indeed, he thinks that recognition of this very fact is crucial for arriving at the correct laws governing the very phenomena under consideration. The idea that beams might be constituted by rigid blocks such as $\mathrm{ABKC}$ is thus patently artificial both by the lights of Leibniz's general natural philosophy as well as by the specific principles guiding his attack on the very problem of rigid beams. Second, each thread binding one element to another element is conceived as a flexible spring, that is, as a flexible, but resisting body. But, of course, it is precisely the phenomena of flexible, resisting bodies that is under investigation in the case of rigid beams. Leibniz couldn't possibly think that the literal postulation of little springs could explain the resistance of rigid beams - such a suggestion could only push the explanatory problem back a step since we would then need an account of the resistance of the little springs. Leibniz's use of tiny springs is thus, once again, I think, best understood not so much an idealization - that is, as an intentional exaggeration of the actual properties of the beam - but rather as a 
fictionalization, an attempt to make the problem of finding the laws governing rigid beams more tractable by thinking of them in patently artificial terms.

And remarkably, Leibniz's fictionalized model does indeed make the original problem of finding an equation governing rigid beams more tractable by showing how beams may be treated as instances of optimal form. In the simplest of terms, an optimal form is a form or structure that (locally) minimizes or maximizes some quantity. Perhaps the most familiar case in which Leibniz applies the notion of an optimal form is in optics, where he argues that rays of light travel along easiest paths, where "ease" is a quantity that can be calculated from the distance the ray travels and the kinds of mediums it traverses. ${ }^{7}$ To see how rigid beams may be thought of as instances of optimal form, it may be helpful to begin by imagining a beam divided into five elements and arranged in two different configurations as in Figures 4 and 5:

${ }^{7}$ For an introductory discussions of optimal form see Hildebrant and Tromba (1985) and Lemons (1997). For discussion of Leibniz's optics in connection with optimal form, see McDonough (2010; forthcoming-a). 


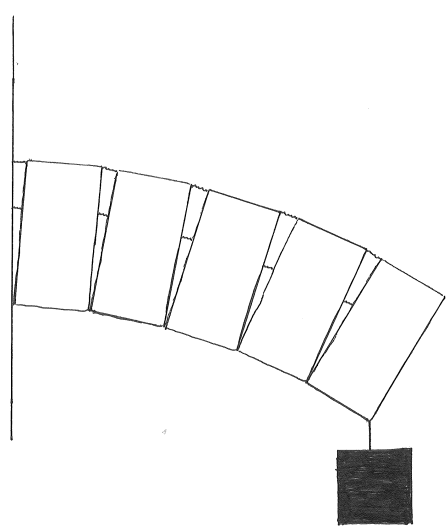

Figure 4

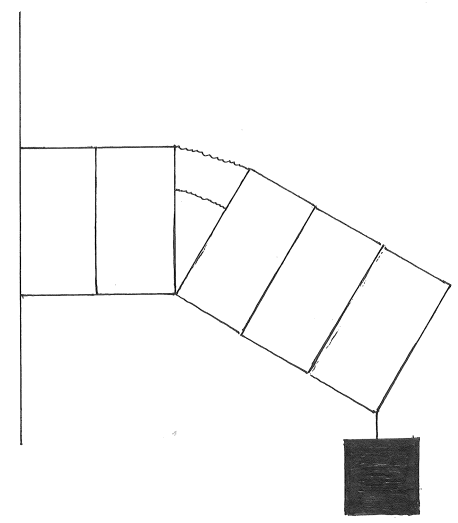

Figure 5

Left to their own devices, weighted beams generally assume configurations that minimize their overall stress energy as in Figure 4. That they should do so is presumably a contingent fact, but one so intuitive as to seem almost self-evident. It's hard to even imagine how a truly uniform beam might come to assume a configuration such as that represented in Figure 5. Confronted by such a configuration we naturally assume that the beam is 
not really uniform after all, or that there must be some cause external to the system that is responsible for the beam assuming a configuration that does not minimize stress energy.

Although Figure 4 represents an optimal configuration of a beam divided into five rigid sections, a moment's reflection will suggest that we can improve upon even its configuration by dividing the beam into more elements, as in Figure 6:

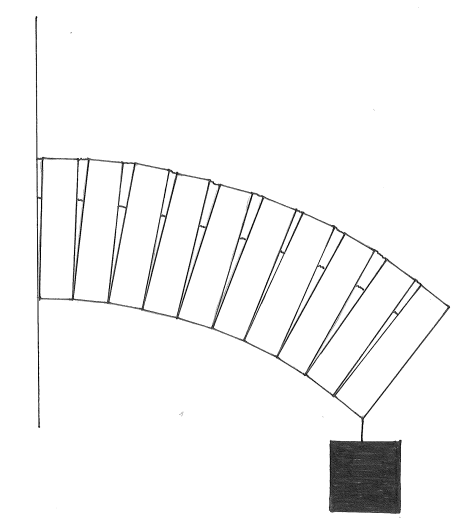

Figure 6

The beam in Figure 6 stores less stress energy than the beam in Figure 4 for essentially the same reason that the beam in Figure 4 stores less stress energy than the beam in Figure 5. And, indeed, it is characteristic of Leibniz's thinking about special problems in mechanics to suppose that the truths of mechanics should not be dependent upon scale - just as we find non-optimality unacceptable in the large, so we should find it unacceptable in the small. But once we recognize that the beam can more closely approach an optimal form as it is divided into smaller elements, it should be clear that the best configuration of the beam - best in the sense of best minimizing its stress energy - will never be obtained as long as the beam is divided into a finite number of elements, each having some finite length. The optimal configuration of the beam will occur in the limit as the number of elements goes to infinity and length of each element approaches zero. An optimally configured beam will thus be a continuous beam in which stored energy is distributed continuously.

In the continuous case, however, something almost miraculous happens: the two patently artificial assumptions made by Leibniz, having served their purpose, disappear. The postulation of rigid elements and elastic springs allows Leibniz to skirt a problem ultimately rooted in the fact 
that the cohesive forces holding elements together are of a different dimensional order than are the gravitational forces drawing the elements downward. The cohesive forces, in short, act on two-dimensional surfaces, while gravitational forces act on points. With the beam conceived of as rigid elements and elastic springs, Leibniz can, as we've seen, treat the problem of determining the resistance of beams as a constrained equilibrium problem and effectively work around the dimensional problem. In the limit however, the dimensional difference between surface and gravitational forces vanishes just as we lose our grip on how we might think of the beam as being composed of extended blocks and extended springs. That is to say, in the continuous case, the dimensional problem and the patently artificial postulates used to work around it disappear together, and we may think of the beam as possessing a continuous distribution of resistive forces acting at points. We have the remarkable, but not uncommon, situation in which the observable properties of gross bodies are successfully related to unobservable point properties via the mediation of patently artificial models. The observable properties provide us with our only grip on the values of the point properties, and yet the point properties provide us with our best means of thinking about the properties of apparently continuous, uniform bodies. ${ }^{8}$

Does Leibniz's analysis of the strength of rigid beams provide us with a new, unexpected argument for monads? Not directly. What it shows most directly is one useful way of relating the observable forces governing extended bodies to the point forces that are revealed by application of the infinitesimal calculus as the lengths of beam segments are pushed to zero. Perhaps almost as directly, it also offers an intriguing prima facie reason for thinking that those point forces have some sort of privilege over the observable forces governing a beam. For all that, however, one could still view Leibniz's analysis instrumentally. That is, one might hold that thinking in terms of point forces is a helpful way of arriving at good equations, but a way that needn't commit us to the existence of anything unextended. The most immediate value of Leibniz's analysis of rigid beams is thus not to be found in a new, direct argument for monads, but rather in its offering an exceptionally elegant model of how extended bodies and their forces might relate to unextended monads and their forces. The next two sections will attempt to develop that model, first with respect to Leibniz's understanding

${ }^{8}$ For a more detailed discussion - from which I have benefited - of the points made in this paragraph, see Wilson (2010). See also Batterman (2001). 
of derivative and primitive forces, second with respect to extended bodies and unextended monads.

\section{A Model for Leibnizian Forces}

Leibniz's mature dynamics is structured principally by two orthogonally drawn distinctions. The first distinction separates "active" from "passive" forces. Intuitively, active forces correspond to a creature's intrinsic ability to bring about change. Leibniz distinguishes between two kinds of active force. The first is what Leibniz terms "living force" or "vis viva." A body's living force corresponds to its ability to bring about change in virtue of its motion. A fast-moving baseball, for example, will have more living force than a slow-moving baseball (all other things being equal of course). The second is what Leibniz terms "dead force" or "vis mortua." A body's dead force is perhaps best thought of as a tendency, or striving, to produce vis viva. Thus Leibniz tells us, for example, that although "motion does not yet exist in" dead force, dead force is nonetheless "a solicitation to motion, as with a ... stone in a sling while it is still being held by a rope ... and [is] also the force of heaviness ... and the force by which a stretched elastic body begins to restore itself' (GM 6:238-9/AG 121-122). While the details of the integration may have remained unsettled, it's clear that Leibniz thinks of dead forces as being quantitatively related to living forces by an infinite summation.

The second principal distinction of Leibniz's mature dynamics separates primitive forces from derivative forces. If we restrict ourselves as Leibniz himself usually does - to active forces, we can say that primitive forces correspond to the internal strivings of immaterial substances ( $G$ 4:395/AG 252). Thus, in a well-known letter of 1704 or 1705, Leibniz tells De Volder, "I think that it is clear that primitive forces can be nothing other than the internal strivings of simple substances, by which they pass from perception to perception in accordance with a certain law of their nature" (G 2:275/LDV 318). Active primitive forces are thus the forces internal to monads that drive them from one perceptual state to the next.

As their name suggests, Leibniz conceives of derivative forces as being in some sense dependent upon, or derived from, primitive forces. His use of the term "derivative force," is, however, ambiguous. In one sense, "derivative force" connotes the instantaneous states of enduring primitive forces. Thus in another letter to De Volder of January 21, 1704, Leibniz writes: "Derivative force is the present state itself insofar as it tends toward a following state, i.e., preinvolves a following state, just as everything in the 
present is pregnant with the future. But the persisting thing itself, insofar as it involves all cases, has primitive force, so that primitive force is like the law of the series, and derivative force is like a determination that designates some term in the series" (G 2:262/LDV 286). Here the term "derivative force" is used to draw a contrast at the deepest level of reality, a contrast between instantaneous states and the enduring entities whose states they are. More often, however, Leibniz uses the term "derivative force" to connote the forces that are manifest in everyday experience and studied by working physicists. Thus, for example, in yet another letter to De Volder of June 20, 1703, Leibniz explains:

Properly and rigorously speaking, perhaps one will not say that the primitive entelechy impels the mass of its body, but only that it is joined with a primitive passive power that it completes, i.e., with which it constitutes a monad. However, it cannot influence other entelechies and substances, even those existing in the same mass. But in the phenomena, i.e., in the resulting aggregate, everything is indeed explained mechanically, and masses are understood to impel one another. And in these phenomena nothing is needed except the consideration of derivative forces, once it is agreed where they result from, namely, the phenomena of aggregates from the reality of monads. (G 2:250/LDV 260)

The term "derivative force" as used here still picks out forces that are dependent upon enduring primitive forces, and perhaps one could agree that in some non-strict sense they are the "same" as the instantaneous states of primitive forces (see Adams 1994, 385). Nonetheless, "derivative force" as used in the passage just quoted has a different meaning or connotation than it had in the previously quoted passage. As Leibniz usually uses the term, and as we will use it from here on out, "derivative force" draws a contrast between the forces that are, on the one hand, observable in everyday phenomena and studied by working physicists, and, on the other hand, the forces that Leibniz thinks are to be found at a deeper level of reality, and which are metaphysically presupposed by observable forces.

Filling in the details of the relationship between Leibniz's derivative forces (so understood) and primitive forces has been described as "probably the largest obstacle to understanding the relationship between Leibniz's physics and Leibnizian metaphysics" (Adams 1994, 378). Leibniz's analysis of rigid beams, however, suggests a rather elegant model for relating the two. For the observable forces governing extended beams should count, for Leibniz, as instances of derivative force. More specifically, the observable forces that govern a beam's restoration after the removal of 
a load should correspond to derivative active forces while the observable forces governing a beam's deformation under the burden of a load should correspond to derivative passive forces. If Leibnizian derivative forces correspond to the observable forces of rigid beams, however, it seems reasonable to suppose that Leibnizian primitive forces should correspond to the unobservable point forces that Leibniz argues must be present in the limit as the length of the beam's segments goes to zero. Those point forces should be counted as active or passive insofar as they are arrived at as the limits of active or passive derivative forces. This core suggestion might be fleshed out further by highlighting five specific features of the relationship between derivative and primitive forces suggested by Leibniz's rigid beams model and by showing how those features are mirrored in a more familiar indeed paradigmatic - example of mechanistic reduction, namely the reduction of observable heat to motions of particles.

First, and perhaps most obviously, both the mechanists' reduction of observable heat and Leibniz's reduction of observable forces are asymmetric. The mechanists' reduction of observable heat to particle motions is asymmetric insofar as mechanists hold that the motions of unobservable particles are ontologically and explanatorily deeper than observable heat itself. Heat, per se, is thus to be explained in terms of particle motions, but particle motions, per se, are not to be explained in terms of heat. On the rigid beams model, Leibniz's reduction of observable forces to primitive forces is likewise asymmetric insofar as it suggests that primitive forces are ontologically and explanatorily deeper than derivative forces (see, for example, G 2:270/LDV 304-306). Derivative forces, per se, are to be explained in terms of primitive forces, but primitive forces, per se, are not to be explained in terms of derivative forces. Indeed, one especially intriguing aspect of Leibniz's technical treatment of rigid beams, as we have seen, is that his very analysis gives him some grounds for supposing that explanations in terms of derivative "extended" forces must ultimately be grounded in primitive "point" forces.

Second, both cases of reduction are non-eliminative. The mechanists' reduction of heat to particle motions is non-eliminative insofar as mechanists typically do not mean to deny that heat exists or that it may legitimately figure in higher-level explanations. In maintaining that heat per $s e$ is to be explained in terms of particle motions, mechanists don't typically mean to deny, for example, that the sun, my stove, and the campfire are all hot. Nor do they mean to deny that the sun's heat warms the sandy beach, that the stove's heat cooks my dinner, or that the heat of the campfire burns the marshmallow. Leibniz's reduction of observable forces to 
primitive forces is similarly non-eliminative insofar as he allows that the explanation of derivative forces in terms of primitive forces is consistent with maintaining that derivative forces exist and may legitimately figure in higher-level explanations. Like the mechanist, Leibniz can maintain that the reduction of derivative forces to primitive forces in no way implies the unreality of derivative forces governing, for example, hammers, nails and boards, and is perfectly consistent with insisting that those derivative forces may be appealed to in order to explain the behavior and interactions of extended bodies.

Third, both cases of reduction might be said to be heterogeneous in light of the nature of the idealizations they take for granted. In suggesting that heat reduces to motions of particles, mechanists do not typically insist that putatively uniform regions of heat must reduce to uniform particle speeds. Rather they insist only that uniform regions of heat must reduce to averaged particle speeds. Consequently, even if, for example, we assume that a room has a uniform temperature, the mechanists' reduction of heat to particle motions is perfectly consistent with the supposition that no two particles in the room move with exactly the same speed. Leibniz's reduction, should, I think, be understood as involving a similar idealization. In reducing derivative forces to primitive forces, Leibniz needn't insist that putatively uniform regions of derivative force must reduce to uniform primitive forces. He can allow instead that uniform regions of derivative force must reduce merely to "averaged" primitive forces. Consequently, even if, for example, we assume that an extended beam has a uniform force for resisting deformation, Leibniz's reduction is perfectly consistent with no two of its grounding primitive forces being exactly the same. A happy result, of course, if primitive forces are to be identified with the internal strivings of monads given the natural assumption that, for Leibniz, no two internal strivings of monads may be exactly the same.

Fourth, although both cases of reduction are broadly quantitative, they are nonetheless non-mereological. It is, of course, central to the mechanists' proposal that there is a quantitative relationship between heat and (averaged) particle speeds. Crudely: the greater the particle speeds the greater the heat. In spite of being quantitatively related, however, particle motions do not stand in a part-whole relation to observable heat. Particle motions aren't literally parts of heat in the way that, say, bricks are literally parts of a brick house. It is similarly central to Leibniz's reduction that there is at least a broadly quantitative relationship between derivative forces and primitive forces. Crudely: the greater, or more forceful, the primitive forces, the greater, or more forceful the derivative forces. Nonetheless, primitive 
forces just as clearly do not stand in a part-whole relation to derivative forces. Primitive forces are no more literally parts of derivative forces than are particle motions literally parts of heat. In spite of being broadly quantitative, the relationship between primitive forces and derivative forces is thus similarly non-mereological.

Finally, fifth, in spite of being non-mereological, both cases are best understood as being local. The mechanists' reduction of heat to particle motions is local in the sense that the observable heat of a given region is taken to reduce to particle motions located in the same general region, even though, as we've just seen, particle motions are not literally parts of the heat that they ground. If a sandy beach is hot, the heat of the beach must be in the same general location as the motions of the particles that realize that heat, and this in spite of the fact that the motions of the particles are not parts of the heat in the same way as the grains of sand are parts of the beach itself. Leibniz's reduction of derivative forces to primitive forces is similarly local in spite of being non-mereological. The derivative forces in a given region must reduce to primitive forces located in the same general region even though, as we've just seen, primitive forces are not literally parts of the derivative forces they ground. The derivative forces that make an extended beam resistant to deformation, and the primitive forces that ground those derivative forces, should thus be thought - on the rigid beams model - to be located at least roughly in the same place, even though primitive forces do not constitute derivative forces in the way that plastic pieces might constitute a toy car. As should become clearer in the next section, this implication of the rigid beams model has especially important consequences for understanding the relationship between extended Leibnizian bodies and unextended Leibnizian monads.

The relationship between Leibniz's derivative and primitive forces has long seemed obscure. The aim of this section has been to show how Leibniz's technical work on rigid beams may help to flesh out this crucial seam in his philosophical system. To briefly take stock: Leibniz's approach to the technical problem of finding an equation governing the strengths of rigid beams suggests that the relationship between derivative and primitive forces may be characterized by five distinctive properties. That is to say, more specifically, the relationship between Leibnizian derivative and primitive forces may be characterized as being asymmetric, non-eliminative, heterogeneous, non-mereological and local. The next section will argue that such an understanding of the relationship between Leibnizian derivative and primitive forces may be used in turn to shed needed light on the 
relationship between extended Leibnizian bodies and unextended Leibnizian monads.

\section{A Model for Leibnizian Bodies}

What, according to Leibniz, is the relationship between extended bodies and the substances that are supposed to serve as their foundations? For the past twenty-five years or so, answers to this question have largely been shaped by two paradigmatic interpretations of Leibniz's metaphysics. On the one hand, idealist interpretations suggest that Leibniz's metaphysical foundations are exhausted by unextended, immaterial substances, and that bodies are related to immaterial substances as their perceptions or thoughts (or contents thereof). ${ }^{9}$ One well-known difficulty for idealist interpretations is that Leibniz often suggests that bodies are "aggregates" of substances and that substances are "in" bodies, and it is difficult to make sense of how bodies could be aggregates of substances, and how substances could be in bodies, if bodies are nothing more than perceptions or thoughts (or contents thereof) had or enjoyed by substances. Corporeal substance interpretations, on the other hand, maintain that, for at least a significant stretch of his career, the foundations of Leibniz's metaphysics are exhausted by extended, corporeal substances, and that bodies are related to corporeal substances roughly as constituents to aggregates. ${ }^{10}$ As long as the foundations of Leibniz's metaphysics are taken to be exhausted by corporeal substances, corporeal substance interpretations can make good sense of how bodies may be aggregates of substances, and how substances may be in bodies. As noted in the introduction, however, almost all commentators concede that at some point the foundations of Leibniz's metaphysics turns monadic. After that point - whenever it might be corporeal substance interpretations offer no insight into how to make sense of the relationship between extended bodies and the unextended, immaterial substances of Leibniz's most mature metaphysics.

In light of the difficulties facing both idealist and corporeal substance interpretations, leading commentators have recently begun to revitalize a third, long-neglected interpretation of Leibniz's mature metaphysics. What we might call non-mereological realist interpretations suggest

${ }^{9}$ For sophisticated developments of this line of thought, see, for example, Adams (1994), Furth (1967), and Rutherford (1990, 1995).

${ }^{10}$ For sophisticated developments of this line of thought, see, for example, Broad (1975, 49-86), Garber (1985; 2009), and Phemister (1999; 2005).

"Leibniz and the Foundations of Physics: The Later Years," to appear in 16 The Philosophical Review, submitted 2015. 
that, for Leibniz, extended bodies are (at least partially) constituted by monads but that monads are nonetheless not parts of the extended bodies they constitute. ${ }^{11}$ Since they take substances to be immaterial and unextended, non-mereological realist interpretations can promise - like idealist interpretations - to make sense of even Leibniz's most mature metaphysics. Since they suggest that bodies are constituted by substances, non-mereological realist interpretations can also promise - like corporeal substance interpretations - a straightforward account of how bodies may be aggregates of substances and how substances may be in bodies. So far so promising, but an obvious difficulty looms: it remains unclear how exactly Leibniz could think that monads might constitute extended bodies while also maintaining that monads are not literally parts of the bodies they constitute. It has been suggested that we might understand this relationship as being analogous to the relationship between the manifest image of ordinary experience and the scientific-image of contemporary science (Garber 2009, 383-384; Rutherford 2008, 149, 153-154). That is right, I think, as far as it goes, but in itself it doesn't go all that far. Gestures towards the mysteries of how the world as we know it might be constituted by quarks, leptons and bosons, or even "strings" in a ten-dimensional space don't give us much of a grip on how Leibniz himself could have thought that extended bodies could be aggregates of unextended monads. What we'd like is a concrete model - ideally one that Leibniz himself would have recognized -that makes it clearer how, exactly, extended bodies might be constituted by unextended monads without monads standing in a partwhole relationship to the those bodies.

Here again attention to Leibniz's technical work on rigid beams proves extremely helpful. For in providing a sophisticated model of the relationship between derivative and primitive forces, Leibniz's work on rigid beams also suggests a concrete model of the relationship between extended bodies and unextended monads. And, indeed, that it should do so should really come as no surprise. For Leibniz maintains that the properties of extended bodies must be grounded in their dynamic properties. ${ }^{12} \mathrm{He}$

${ }^{11}$ For sophisticated developments of this line of thought, see, for example, Arthur and Loptson (2006, 21-33), Hartz (1992; 2007), Jolley (1986), and Rutherford (2008).

12 The grounding relation has, of course, been the focus of much recent research. For a route into the current debate, see Fine (2012), Rosen (2010), and Schaffer (2009). For discussion of grounding specifically in connection with Leibniz, see Della Rocca (2012) and McDonough (forthcoming-b). 
insists that not only so-called secondary qualities like heaviness, heat and color but also primary qualities like "figure, motion and extension" must be rooted in derivative forces. But, as we've just seen, he also maintains that derivative forces must be grounded in primitive forces, that is, that the dynamic properties of observable bodies must be grounded in the dynamic properties of unobservable monads. In providing a model of how derivative forces are grounded in primitive forces, Leibniz's work on rigid beams might therefore be expected to also provide a model of how extended bodies are grounded in unextended monads. In order to develop that suggestion further, it may be helpful to revisit the five properties highlighted in the previous section, this time with an eye turned specifically to how those properties might flesh out Leibniz's understanding of the relationship between extended bodies and unextended monads.

First, and again most obviously, just as Leibniz's grounding of derivative forces in primitive forces is asymmetric, so too his grounding of extended bodies in unextended monads is asymmetric. Indeed, this asymmetry may be seen as lying behind Leibniz's famous declarations of monadic foundationalism. Thus, for example, near the beginning of The Principles of Nature and Grace, Leibniz emphasizes, "There must be simple substances everywhere, because without simples, there would be no composites" (G 6:598/AG 207). Likewise, the Monadology famously begins: "The Monad, which we shall discuss here, is nothing but a simple substance that enters into composites ... And there must be simple substances, since there are composites; for the composite is nothing more than a collection, or aggregate, of simples. ... These monads are the true atoms of nature, and, in brief, the elements of things" (G: 6:607/AG 213). Such passages clearly indicate that, at least in his later years, Leibniz took extended bodies to be asymmetrically grounded in unextended monads. To that central point, two sub-points might be added. (1) Although the rigid beams model implies an asymmetric dependence of extended bodies on unextended monads, it does not per se militate against the existence of extended, corporeal substances. The rigid beams model is perfectly consistent, for example, with a picture of Leibniz's mature metaphysics according to which ordinary bodies are constituted by corporeal substances, which in turn are constituted by incorporeal substances (see, for example, McDonough 2013). (2) In suggesting that extended bodies are asymmetrically grounded in unextended monads, Leibniz's rigid beams model does not preclude the possibility that there might be other explanatory relations running in the opposite direction. Indeed, one intriguing aspect of Leibniz's technical treatment of rigid beams is that while it implies that the forces governing extended bodies 
must be grounded in point forces, it also suggests that our only access to the values of those point forces is through the directly measurable forces governing extended bodies.

Second, just as Leibniz's grounding of derivative forces in primitive forces is non-eliminative, so too his grounding of extended bodies in unextended monads is non-eliminative. Although Leibniz does indeed seem to have flirted with an eliminative, Berkeleyian style idealism, his most considered position suggests that extended bodies are not to be done away with but rather that they are to be grounded, or well-founded, in substances and their perceptions or thoughts. ${ }^{13}$ Thus, for example, in the relatively early New System, Leibniz suggests that bodies would be "only phenomena like very orderly dreams" if - but only if - they were not grounded in true unities "analogous to the soul" (G 4:473-4/WF 23-24). Similarly in a letter to Johann Bernoulli of 1698, Leibniz suggests "there would be nothing in bodies but phantasms" if - but again only if - "there were no souls or something analogous to them," concluding "From this, one can easily judge that there is no part of matter in which monads do not exist" (GM 3:537/AG 167). And finally, in an often cited passage from a letter to De Volder of 1705, Leibniz declares quite explicitly "Indeed, I do not take away (tollo) body, but I reduce it (revoco) to that which it is, for I show that corporeal mass which is believed to have something over and above simple substances is not a substance but a phenomenon resulting from simple substances which alone have unity and absolute reality" (G 2:275/LDV 318). Thus just as Leibniz's mature dynamics suggests that derivative forces are not to be eliminated, but rather grounded in, primitive forces, so his mature metaphysics suggests that extended bodies are not to be eliminated, but rather grounded in, unextended monads.

Third, just as Leibniz's grounding of derivative forces in primitive forces is heterogeneous, so too is his grounding of extended bodies in unextended substances. Earlier it was noted that mechanists typically allow that putatively uniform regions of heat needn't reduce homogeneously to particle motions, so that, say, the putatively uniform temperature of a frying pan might be grounded in the average, but non-uniform, motions of its constituting particles. It was argued above that Leibniz can similarly allow that putatively uniform derivative forces may be grounded in, as it were, "averaged," but non-uniform, primitive forces. Shifting now to the relationship between extended bodies and monads, Leibniz can similarly

${ }^{13}$ For discussion of Leibniz's flirtations with eliminative idealism, see Adams (1994, 224-228); Garber (2009, 267-301); and Wilson (1999). 
insist that putatively uniform extended bodies needn't reduce homogeneously to monads. Indeed, in light of his more general philosophical commitments, it would seem that he must insist that putatively uniform extended bodies don't reduce homogeneously to monads. For on pain of violating the identity of indiscernibles, he must insist that, say, a putatively uniform block of ice, wood or iron must be grounded in monads that are not exactly similar to one another. In this regard, the relationship between extended bodies and unextended monads would seem to have to be, for Leibniz, more closely analogous to the relationship between heat and the motions of its constituting particles than, say, the relationship between the motion of a train and the motion of its constituting cars.

Fourth, just as Leibniz's grounding of derivative forces in primitive forces is non-mereological, so too his grounding of extended bodies in unextended monads is non-mereological. Leibniz suggests that every extended body - no matter how small - is made up of an infinity of monads. There is thus a quantitative relationship between extended bodies and unextended monads just as there are broadly quantitative relationships between derivative and primitive forces as well as between heat and particle motions. As Leibniz repeatedly insists, however, the relationship between extended bodies and unextended monads is not whole-to-part. Thus, for example, in a passage that appears to be related to his notes on the Fardella memo, Leibniz writes:

There are, however, infinite simple substances or creatures in any particle of matter; and matter is composed from these, not as from parts, but as from constitutive principles or [sen] immediate requisites, just as points enter into the essence of a continuum and yet not as parts, for nothing is a part unless it is homogeneous with a whole, but substance is not homogeneous with matter or body no more than a point is with a line. (A 6.4.1673)

Similarly, in a letter to De Volder of June 30,1704, Leibniz writes that the "substantial unities" that ultimately ground material bodies "are not parts" of bodies but rather the foundations of bodies (G 2:268/LDV 302). In denying that monads are parts of matter, Leibniz wishes to resist a certain picture of how unextended monads might be thought to be related to extended bodies: just as a line is not mereologically composed of points, so too an extended body is not mereologically composed of unextended monads. Nonetheless, in affirming that unextended monads compose extended bodies, Leibniz implies that unextended monads do stand in a relationship of composition to extended bodies. These two thoughts are 
consistent because composition isn't necessarily mereological. The schoolhouse may be mereologically composed of bricks, but the frying pan's heat may be non-mereologically composed of the motions of particles. Thus just as Leibniz is able to maintain that derivative forces are grounded in primitive forces without allowing that primitive forces are parts of derivative forces, so too he is able to maintain that extended bodies are grounded in monads without allowing that monads are parts of the bodies they compose.

Fifth, just as Leibniz suggests that primitive forces are located where their derivative forces are located, he also suggests that - in some sense - monads must be located where their bodies are located. Thus, for example, in a letter to De Volder of June 20, 1703, he writes:

I had said that extension is the order of coexisting possible things, and that time is the order of inconsistent possibilities. If this is so, you say that you wonder how time pertains to all things, spiritual things as much as corporeal ones, but extension only to bodies. I reply that the reason is the same in both cases and for both sorts of things, namely that both spiritual and material changes have their home, so to speak, in the order of successive things, or in time, as well as their place in the order of coexisting things, or in space. [i] For even if monads are not extended, they nonetheless have a certain kind of situation in extension, that is, they have a certain ordered relation of coexistence to other things, namely through the machine over which they preside. [ii] I do not think that there exist any finite substances that are separated from every body and, therefore, lack situation or order in relation to the other coexisting things in the universe. Extended things involve in themselves many things endowed with situation. [iii] But things that are simple, even if they do not have extension, must nonetheless have a situation in extension, although it may not be possible to designate it precisely, as with incomplete phenomena. (LDV 266-268)

Here Leibniz seems to be at pains to reject De Volder's suggestion that monads enjoy temporal but not spatial locations. Leibniz argues, on the contrary, that [i] monads have spatial locations - wholly or in part - in virtue of dominating their bodies. That [ii] every monad dominates some body. And so, it would seem to follow that every actual monad must have some spatial location (even if, [iii] due to considerations of the continuum, that spatial location may be specifiable only as falling within a finite neighborhood rather than being at an exact point). 
If it is allowed that monads are literally located within the bodies they dominate, Leibniz's treatment of rigid beams might be viewed as offering a strikingly literal model of how monads relate to extended bodies; that is to say, if it is allowed that monads are literally located within bodies, we might take Leibnizian extended bodies to be literally constituted by monads in essentially the same way as we commonly take heat to be constituted by particle motions. Such an interpretation of Leibniz's mature metaphysics might fairly claim the virtues commonly associated with nonmereological realist interpretations. Even in the context of his most mature, monadic metaphysics, it could make good sense of Leibniz's repeated claims that extended bodies are "aggregates" of substances and that substances are "in" bodies. Furthermore, it could do so without having to appeal apologetically to the mysteries of contemporary physics - to quarks or leptons or strings in ten dimensional space. The need for a concrete model - always the Achilles heel of realist non-mereological realist readings - might finally be filled by a sober, sophisticated exemplar drawn from Leibniz's own scientific studies. But can monads literally be located where their bodies are located? Can they, like bodies, exist not just in time but also in space? While this is not the place to try to settle the issue once and for all, the next section will attempt to at least reopen the question of the spatiality of monads. It argues that in spite of some important qualifications, there are good textual and contextual reasons for supposing that Leibniz might have held that monads enjoy spatial locations.

\section{Can Monads Be Spatial?}

The question of whether monads can be spatial is complicated by a number of well-known subtleties of Leibniz's system. ${ }^{14}$ At root, those subtleties might be thought to flow from two commitments in particular. The first commitment is that monads are themselves unextended. As a consequence, they cannot enjoy locations in Aristotle's sense, that is, they can't enjoy locations defined in terms of enveloping surfaces. Nor can they enjoy locations in what we might think of as Newton's sense, that is, in the sense of fully occupying finite regions or volumes. Nor finally - as we've seen - can monads enjoy locations in virtue of being literal parts of things that themselves enjoy locations. The second commitment concerns

${ }^{14}$ For helpful discussions of Leibniz's views on space see, for starters, Arthur (2013), Broad (1981), De Risi (2007), Hartz and Cover (1988), and Winterborne (1982).

"Leibniz and the Foundations of Physics: The Later Years," to appear in 22 The Philosophical Review, submitted 2015. 
Leibniz's understanding of space. Since Leibnizian space is relational, monads can't be spatial in virtue of being located within an ontologically independent, substantival space. Furthermore, since Leibnizian space is continuous, and monadic reality discrete, monads can't be located at specific spatial points; the continuous and the discrete are, for Leibniz, in general, incommensurable. ${ }^{15}$ Finally, since Leibniz maintains that, strictly speaking, space itself is ideal entity, monads can't, strictly speaking, be in space any more than they can be in an ideal square or an ideal circle (see, for example, LDV 130, G IV 568, G IV 491-92).

Such subtleties, however, would seem to leave open the possibility that Leibniz takes monads to be located where their bodies are located. That is, that he would agree, for example, that when he was living in Paris that not only was his body located in the French capital, but that his soul, his body's dominant monad, was there too. Indeed, the subtleties of the previous paragraph would seem to be consistent with monads being spatially located in a more specific sense. The location of a monad might be specifiable by the volume of a surrounding body taken as small as one likes. So, for example, Leibniz could hold that if a monad is located in a beam, it must be located in one half or other of the beam; and whatever half it is located in, it must be located in one half or other of that half, and so on as far as one wishes to go (cf. G II 100/AG 88; NE 221). Such a picture offers one sense in which monads might enjoy spatial locations without apparently violating either of Leibniz's two main complicating commitments. It does not require monads themselves to be extended. As a consequence, it does not require monads to either have surfaces that might be enveloped or to fully occupy finite regions or volumes. Nor does it require monads to be located in a substantival, absolute space. It is therefore prima facie consistent with Leibniz's relationalism about space as well as his reluctance to locate monads at spatial points. With this more specific picture in mind, let's call

${ }^{15}$ In what follows, I assume that Leibniz distinguishes between ideal, continuous extension, on the one hand, and non-ideal, infinitely-divided extension on the other hand (see, for example, LDB 124, LDV 333; G 4:394-5/AG 251-2; G 7:563). If monads are to be located within extended bodies, they will have to be located within extension that is not characterized by continuity. For attempts to contextualize, develop, and make precise the distinction between ideal, continuous extension and nonideal, non-continuous extension, see Arthur (2014, 149-153), (Levey 2005, 2003, 1998), Marshall (2011). For important alternative views see Crockett (2009, 1999), Hartz (1992), Hartz and Cover (1988, especially 507).

"Leibniz and the Foundations of Physics: The Later Years," to appear in 23 The Philosophical Review, submitted 2015. 
the view that, in his mature period, Leibniz standardly took monads to be located within bodies the spatiality thesis.

The spatiality thesis, or something near enough, was once commonly attributed to Leibniz by leading scholars, including, for example, Bertrand Russell (1937, 118-126), Nicholas Rescher (1986, 84-91) and A.T. Winterborne (1982, 201-214). It has, however, clearly fallen out of favor among more recent commentators. Thus, for example, Robert Adams, although he defends a characteristically interesting and subtle view concerning the relationship between monads and bodies, ultimately insists that "monads per se do not have any location" and that "In themselves the monads have no spatial position and no other spatial properties" (1994, 250, 255). Donald Rutherford similarly maintains that "monads, are non-spatial entities," and attributes to Leibniz the alleged insight that "in conceiving of a truly simple thing that is, nonetheless, real, a thing whose determinations are entirely internal, one is limited to thinking of a substance that is not in space and that cannot be used to explain the spatiality of appearances" (2004, 233; see also 1994, 66; 1995, 191, 251). Finally, Daniel Garber, although he expresses uncertainty as to whether Leibniz had a fully considered view concerning the spatiality of monads, concedes, "it is difficult to say exactly how monads can have situation" (2009, 360). The relationship between monads and space is too complex and thorny to be taken up here in full detail. Nonetheless, since the current consensus against the spatiality thesis represents an obvious objection to the interpretation of the foundations of Leibniz's physics developed above, it should be worthwhile to briefly consider three reasons for thinking that the current consensus might be mistaken, and that the previous generation of commentators was right to think that Leibniz takes monads to enjoy at least approximate spatial locations.

A first reason for thinking that Leibniz accepts the spatiality thesis as just described is provided by the numerous passages in which Leibniz explicitly tells us that monads are located in matter or in the bodies they dominate. The passage cited above from Leibniz's letter to De Volder of June 20,1703, in which he states, "even if monads are not extended, they nonetheless have a certain kind of situation in extension," is perhaps the most famous (LDV 266). Also well known is a passage from Leibniz's correspondence with Arnauld in which he suggests that if an insect is divided in half "the soul of the insect will remain only on one side" and that "since, in the formation and growth of the insect, the soul was, from the beginning, in a certain part that was already living, after the destruction of the insect it will still remain in a certain part ... as small as is necessary for it 
to be protected from the action of someone tearing or destroying the body of that insect" (G II 100/AG 88). Other passages to similar effect, however, are not hard to find. Thus, for example, in a letter to Johann Bernoulli dated approximately August-September 1698, Leibniz writes: "But if there were no souls or something analogous to them, then there would be no I [Ego], no monads, no real unities, and therefore there would be no substantial multitudes; indeed, there would be nothing in bodies but phantasms. From this, one can easily judge that there is no part of matter in which monads do not exist" (LDV 8). Likewise in another letter to De Volder dated January 19, 1706, Leibniz writes: "It is also obvious from what I have said that, in actual things, there is only discrete quantity, namely a multitude of monads or simple substances, indeed a multitude greater than any number you choose in every sensible aggregate, that is, in every aggregate corresponding to phenomena" (LDV 332). Finally in a letter to Des Bosses of February 14, 1706, Leibniz writes: "Since monads or principles of substantial unity are everywhere in matter, it follows from this that there is also an actual infinity, for there is no part, or part of a part, that does not contain monads" (LDB 24, see also G 7:565). Passages such as these imply that monads enjoy spatial locations, that monads are "in bodies," "in actual things," "in matter" and so must be located where bodies, things, and matter are located. Paired with the interpretation of the foundations of Leibniz's physics developed above, such passages suggest that, indeed, since the Pont Neuf is in Paris, the monads that make up, constitute, or ground the Pont Neuf must be located in Paris as well.

A second, contextual reason for thinking that Leibniz accepts the spatiality thesis is provided by the views of his predecessors. As Robert Pasnau has recently argued in detail, Leibniz's predecessors seem to have uniformly insisted that all creatures must be located somewhere. ${ }^{16}$ The view that all creatures must enjoy spatial locations is found already in the ancient Greeks. Plato, for example, writes that space "provides a home for all created things, and ... [we] say of all existence that it must of necessity be in some place and occupy a space, but that what is neither in heaven nor in earth has no existence" ([Timaeus 52b] 1989, 1178-1179). Aristotle similarly insists that "The physicist must have a knowledge of place" ... since "all suppose that things which exist are somewhere" while only the "nonexistent is nowhere" ([Physics IV.1, 208a27-30] 1984, 354). The notion that all creatures must be spatially located continued to be upheld throughout

${ }^{16}$ For discussion of the relevant historical background (to which I'm indebted here) see Pasnau (2011, 328-333).

"Leibniz and the Foundations of Physics: The Later Years," to appear in 25 The Philosophical Review, submitted 2015. 
the middle ages. Augustine, for example, allows that nothing so demands his assent as the view that "Whatever exists must exist somewhere" ([Soliloquia I.15.29] 1948, 379). Peter John Olivi, taking up the question of whether angels in particular enjoy locations, concludes that it is impossible for any creature "to have an existence that is absolutely free of every local relation" ([II.32] 1922, 587). And William Ockham, in discussing God's relation to his creatures, simply takes it for granted that "there is no thing that really exists that is nowhere, distant from all things" ([Ordinatio I.37] 1967-1989, 4:568-9). The view that all creatures must enjoy spatial locations persists in the thinking of Leibniz's still more immediate, early modern predecessors. Francisco Suárez, for example, insists, "no thing (res) can be understood that does not exhibit its real presence somewhere ([40.4.19] 1965, 548). Henry More, maintains that, provided that place is not taken as the "Concave superficies of one body immediately environing another body," we can assert that "spirits are as truly in place as bodies" ([Book I, Chapter 10] 1659, 72). Newton concurs, writing, "No being exists or can exist which is not related to space in some way. ... created minds are somewhere, and body is in the space that it occupies; and whatever is neither everywhere nor anywhere does not exist" ([De Gravitatione 4] 2004, 25). The seemingly universal conviction among Leibniz's predecessors and contemporaries that all creatures enjoy spatial locations provides, a powerful prima facie reason for thinking that Leibniz accepted the spatiality thesis as well, that is, for thinking that when he says that monads are located "in bodies," "in actual things," "in matter," we may take him at his word.

A third, also contextual reason, for thinking that Leibniz accepted the spatiality thesis is provided by the views of his immediate successors in the German "Leibnizian" tradition. For the most important figures of that tradition, including Christian Wolff, Alexander Baumgarten, and the early Kant all maintained that the most foundational elements of the created world enjoy spatial locations. Thus, for example, in his Cosmologia Generalis, Wolff suggests that while the most foundational elements of things are unextended, they may nonetheless be "external to each other" so that when they co-exist together in one thing, the resulting aggregate must be extended ([SS 219-221] 1964, 168-170). In his Metaphysics, Baumgarten, states even more explicitly, "single monads have a position $(\$ 148)$, which is either place in simultaneous monads or age in successive monads, or both (\$281)" ([\$397] 2013, 174). And in his Physical Monadology, the early Kant insists, "Each simple element of a body, that is to say, each monad, is not only in space; it also fills a space, though it does not, for that reason, forfeit its simplicity" ([1:480] 1992, 56). The contextual evidence here is, of course, 
indirect. One could see a fundamental parting of the ways between Leibniz and the German Leibnizian tradition. ${ }^{17}$ The reception of Leibniz's metaphysics by his most immediate successors, however, is, I think, more plausibly taken as further evidence that Leibniz's explicit claims that monads are located "in bodies," "in actual things," "in matter" may be taken at face value. Doing otherwise would require us to see Leibniz not only as departing radically from his predecessors, but also from his most immediate successors.

Given the strong textual and contextual evidence in favor of the spatiality thesis, why would anyone think that Leibniz does not hold that monads are spatially located? It should be conceded that the issue of the spatiality of monads intersects with a number of difficult - and uncertain themes in Leibniz's philosophy, and plausible disagreement in other areas might lead to plausible disagreement concerning the spatiality of monads as well. One influential reason for rejecting the spatiality thesis, however, seems to rest on a misunderstanding. It's widely assumed that earlier thinkers held that immaterial entities in general do not, and cannot, enjoy spatial locations. Such an assumption figures, for example, explicitly and centrally in Jan Cover and Glenn Hartz's highly influential attack on the spatiality thesis in their important article "Can Monads be Spatial?" Near the beginning of their essay, Cover and Hartz write: "At first glance Leibniz's monads hardly seem the right sort of thing to be spatially located. In the dualist tradition, immaterial substances are reckoned completely bereft of properties like spatial location: spatiality is a feature only of physical objects, and monads are as mental as things get" (1994, 295). In their concluding remarks, Cover and Hartz return to this "argument from dualism" suggesting that such considerations of "the tradition can scarcely be underplayed," and concluding that with reflection on the dualist tradition and Leibniz's commitment to it "the spatiality thesis emerges with little to recommend it" $(1994,311)$. Given his commitment to a fundamental ontology exhausted by mind-like entities, one might be tempted to quibble over Cover and Hartz's description of Leibniz as a "dualist" (as opposed to, say, a non-eliminative mentalist). In spite of the name they give it, however, Cover and Hartz's "argument from dualism," doesn't really turn on Leibniz's being a dualist at all. The real thrust of their argument is simply that (i) philosophers of the past consistently held that immaterial things

${ }^{17}$ In a rich and provocative paper, Donald Rutherford defends just such an interpretation, arguing that while Wolff's elements are indeed spatial, Leibniz's monads are not (2004). See also Kant (1910-, 7:248).

"Leibniz and the Foundations of Physics: The Later Years," to appear in 27 The Philosophical Review, submitted 2015. 
must lack spatial properties, (ii) Leibniz clearly maintains that monads are immaterial, and so, absent strong evidence to the contrary, we should conclude (iii) Leibniz similarly maintains that monads lack spatial properties. Although not always announced so explicitly, I suspect that a similar line of thought lies behind much of the current consensus against the spatiality thesis.

Widely accepted or not, however, no one should be moved by this allegedly "dualist" line of thought. For the crucial premise that thinkers of the past generally held that immaterial entities must lack spatial properties just isn't true. Some evidence that it is false is provided by the passages cited above. Whether counted as dualists or not, most of Leibniz's predecessors believed in the existence of created immaterial beings including souls, intellects, and angels. They nonetheless all insisted that created beings must exist somewhere. Further evidence that Leibniz's predecessors accepted the spatiality of immaterial beings is provided by the doctrine of holenmerism. Holenmerism is the view that some things may exist not partes extra partes - not parts outside of parts - but rather bolenmerically (or in more scholastic parlance, "definitively"), that is wholly in different parts. Many of Leibniz's predecessors, including Plotinus, Augustine, Anselm, Bonaventure, Aquinas, Scotus, Ockham, Buridan, and arguably even Descartes, held that human immaterial souls exist holenmerically in their respective human bodies (Pasnau 2011, 337). But if bodies enjoy spatial locations, and souls exist where their bodies exist, then souls must enjoy (at least approximate) spatial locations as well. Still further evidence that Leibniz's predecessors were willing to ascribe spatial properties to immaterial entities is provided by the commonly held view - perhaps especially surprising today - that spatial locations can even be ascribed to God. Thus, for example, Anselm argues that God can neither exist "nowhere and never," nor "somewhere and sometime," and so must exist "everywhere and always" ([Monologium, chapter 20] 1998, 33-34). Scotus similarly insists that it cannot be "said that God is nowhere, since that seems to be a characteristic of nothing," adding that "one must say that God is everywhere through his essence" ([Reportatio A I.37.1-2 n.27] 2008, 444). Similarly, Suárez maintains that "God is intimately present to this corporeal universe, not only by presence (that is, cognitively) and by power or action, but also by his essence or substance, just as all theologians teach, as certain to the faith, on account of divine immensity" ([50.3.8] 1965, 984). The evidence thus suggests that it is just not true that philosophers once generally held that "spatiality is a feature only of physical objects." Indeed, exactly the opposite conclusion seems in order: philosophers of the past 
commonly held that immaterial things must enjoy spatial locations. It is, of course, still possible that Leibniz meant to break with this tradition as well. Nonetheless the case against the spatiality thesis seems far less compelling than is widely assumed. If our best understanding of Leibniz's work in physics proves inconsistent with the non-spatiality of monads, we should certainly be prepared, I think, to reconsider his commitment to the latter in developing the former.

\section{Conclusion}

The primary aim of the present essay has been to show how attention to Leibniz's neglected work on rigid beams may help to shed light on his understanding of the relationship between his sophisticated physics and his foundational metaphysics. The first section accordingly revisited Leibniz's approach to the technical problem of determining the breaking strengths of loaded beams fixed at one end. That work, it was argued, suggests a sophisticated, but not unintuitive model of the relationship between observable forces governing extended bodies and unobservable "point" forces. The second section argued that Leibniz's rigid beams model further offers a way of understanding the relationship between his derivative and primitive forces. Very roughly, Leibniz's derivative forces may be grounded in primitive forces in much the same way as the observable forces governing extended beams may be grounded in unobservable point forces. The third section argued that such an understanding of the relationship between Leibniz's derivative and primitive forces in turn provides insight into Leibniz's understanding of the relationship between extended bodies and unextended monads. Very roughly, since Leibniz takes the properties of extended bodies to be grounded in their dynamic properties, and the properties of monads to be grounded in their dynamic properties, in providing a model of how derivative forces are grounded in primitive forces, Leibniz's work on rigid beams also provides an account of how extended bodies may be grounded in unextended monads. Finally, the fourth section took up a likely objection to the account offered in the previous sections. It argued - contrary to current consensus - that monads may in fact be spatially located in the sense that they may be located at least approximately where their extended bodies are located.

A secondary, more general aim of the present essay has been to draw - or redraw - attention to what might be thought of as the neglected theme of Daniel Garber's seminal Leibniz and the Foundations of Physics: The Middle Years. In that paper, Garber effectively linked two themes for a 
generation of Leibniz scholars. The first theme concerned the relationship between Leibniz's physics and his foundational metaphysics. To what extent are there rich, interesting relations between Leibniz's considerable scientific accomplishments and his seemingly fantastic metaphysical speculations? The second theme concerned the status of corporeal substances in Leibniz's philosophy. Did Leibniz think that the world is constituted by extended, corporeal substances, and if so, for how long? Garber conjectured that the two themes are related, that in his middle years Leibniz's metaphysics of corporeal substances provides his physics with an intelligible, realist foundation for his physics and that it is only later, after he "put aside his serious work in physics," and after his science loses "its grip on reality" that Leibniz introduces incorporeal substances $(1985,99)$. Over the past thirty years or so, a tremendous amount of work has been devoted to exploring Garber's second theme and much progress has been made in understanding the evolution and complexity of Leibniz's views on substance. Garber's first, and I think even more interesting theme, however, has received far less attention. Armed now with a better appreciation of the foundations of Leibniz's metaphysics, the time is ripe to reconsider its relations to his sophisticated scientific studies. If his work on rigid beams is any indication, Leibniz's thinking about the foundations of his physics may well prove to be every bit as interesting, subtle and challenging as his thinking about the foundations of his metaphysics.

\section{List of Abbreviations}

A = Deutsche Akademie der Wissenschaften, ed., Gotfried Wilhelm Leibniæ: Sämtliche Schriften und Briefe (Darmstadt and Berlin: Akademie-Verlag, 1923-), cited by series, volume, and page.

AG $=$ R. Ariew and D. Garber, ed. and trans., Philosophical Essays

(Indianapolis: Hackett, 1989).

G = C. I. Gerhardt, ed., Die Philosophische Schriften von Gottfried Wilhelm

Leibniz. (Berlin: Weidmann, 1875-90; repr. Hildesheim: Olms, 1960).

Reference is to volume and page.

GM = C. I. Gerhardt, ed., Mathematische Schriften von Gotfried Wilhelm Leibnir, Berlin: A. Asher; Halle: H.W. Schmidt, 1849-63. Reference is to volume and page. 
LDB $=$ Brandon C. Look and Donald Rutherford, ed. and trans., The

Leibniz-Des Bosses Correspondence (New Haven: Yale University Press, 2007).

Reference is to original language page.

LDV = Paul Lodge, ed. and trans., The Leibniz-De Volder Correspondence

(New Haven: Yale University Press, 2013). Reference is to original language page.

$\mathrm{NE}=\mathrm{P}$. Remnant and J. Bennett, ed. and trans., New Essays on Human Understanding (Cambridge: Cambridge University Press 1996) reference is to book, chapter, section.

WF $=$ R. Woolhouse and R. Franks, ed. and trans., Leibniz's "New System" and Associated Texts (Oxford: Oxford University Press 2006).

\section{Bibliography}

Adams, Robert. 1994. Leibniæ: Determinist, Theist, Idealist. New York: Oxford University Press.

Anselm. 1998. The Major Works, ed. Brian Davies and G. R. Evans. New York: Oxford University Press.

Aristotle. 1995. The Complete Works of Aristotle, Volume I, ed. Jonathan Barnes. Princeton, NJ: Princeton University Press.

Arthur, Richard, T. W. 2014. Leibniæ: Malden, MA: Polity Press.

----. 2013. "Leibniz's Theory of Space.” Foundations of Science 18(3): 499-528.

Arthur, Richard T. W. and Peter Loptson. 2006. "Leibniz's Body Realism: Two Interpretations." The Leibniz Review 16: 1-42.

Augustine. 1948. The Happy Life; Answer to Skeptics; Divine Providence and the Problem of Evil; Soliloquies. The Fathers of the Church: A New Translation, Volume 5, trans. Ludwig Schopp. Washington, D.C.: The Catholic University of America Press. 
Baumgarten, Alexander. 2013. Metaphysics, A Critical Translation with Kant's Elucidations, Selected Notes, and Related Materials, trans. and ed. Courtney D. Fugate and John Hymers. New York: Bloomsbury.

Batterman, Robert. 2001. The Devil in the Details: Asymptotic Reasoning in Explanation, Reduction and Emergence. Oxford: Oxford University Press.

Benvenuto, Edoardo. 1991. An Introduction to the History of Structural Mechanics, Part 1: Statics and Resistance of Solids. New York: Springer-Verlag.

Broad, C. D. 1975. Leibniz: An Introduction. Cambridge: Cambridge University Press.

----. 1981. "Leibniz's Last Controversy with the Newtonians." In Leibniæ: Metaphysics and Philosophy of Science, ed. R.S. Woolhouse, 157-74. Oxford: Oxford University Press.

Cover, J. A. and Glenn A. Hartz. 1994. "Are Leibnizian Monads Spatial?” History of Philosophy Quarterly 11(3): 295-316.

Crockett, Timothy. 2009. "The Fluid Plenum: Leibniz on Surfaces and the Individuation of Body." British Journal for the History of Philosophy 17(4): 73567.

---- 1999. "Continuity in Leibniz's Mature Metaphysics." Pbilosophical Studies 94(1-2): 119-38.

Della Rocca, Michael. 2012. "Violations of the Principle of Sufficient Reason in Leibniz and Spinoza." In Metaphysical Grounding: Understanding the Structure of Reality, ed. Fabrice Correia and Benjamin Schnieder, 139-64. Cambridge: Cambridge University Press.

Fine, Kit. 2012. "Guide to Ground." in Metaphysical Grounding: Understanding the Structure of Reality, ed. Fabrice Correia and Benjamin Schnieder, 37-80. Cambridge: Cambridge University Press.

Furth, Montgomery. 1967. "Monadology." The Philosophical Review 76: 169200. 
Galileo, Galilei, 1890-1910. Opere di Galileo Galilei, ed. A. Favaro. Florence: Successori Le Monnier. Reference is to volume and page.

----. 1974. Galileo Galilei: Two New Sciences, trans. Stillman Drake. Madison: The University of Wisconsin Press.

Garber, Daniel. 1985. "Leibniz and the Foundations of Physics: The Middle Years." In The Natural Philosophy of Leibniz, ed. K. Okruhlik and J. R. Brown, 27-130. Dordrecht: Reidel.

---- 1995. "Leibniz: Physics and Philosophy." In The Cambridge Companion to Leibniæ, ed. Nicholas Jolley. New York: Cambridge University Press.

---- 2009. Leibniæ: Body, Substance, Monad. New York: Oxford University Press.

Gueroult, Martial. 1967. Leibniæ: Dynamique et Métaphysique. Paris: AubierMontaigne.

Hartz, Glenn A. 1992. "Leibniz's Phenomenalisms." The Philosophical Review 101: 511-49.

----. 2007. Leibniz's Final System: Monads, Matter and Animals. New York: Routledge.

Hartz, Glenn and J. A. Cover. 1988. "Space and Time in the Leibnizian Metaphysic." Noûs 22: 493-519.

Hecht, Hartmut. 1992. Mathematik und Naturwissenschaften im Paradigma der Metaphysik. Stutgart: B. G. Teubner Verlagsgesellschaft.

Hildebrandt, Stefan and Anthony Tromba. 1985. Mathematics and Optimal Form. New York: Scientific American Books.

Jolley, Nicholas. 1986. "Leibniz and Phenomenalism." Studia Leibnitiana 18: 38-51.

Kant, Immanuel. 1992. Theoretical Philosophy 1755-1770, trans. and ed. David Walford, with Ralf Meerbote. New York: Cambridge University Press. 
----. 1910-. GesammelteSchriften und Briefe, ed. Akademie der Wissenshaften. Berlin: Reimer, later DeGruyter. Cited by volume and page.

Leibniz, G. W. 1684. "Demonstrationes Novae De Resistentia Solidorum" Acta eruditorum, 319-25. Leipzig. Reprinted in GM 6:106-112. Citation is to the original.

Lemons, Don. 1997. Perfect Form: V ariational Principles, Methods, and Applications in Elementary Physics. Princeton, New Jersey: Princeton University Press.

Levey, Samuel. 2011. "On Two Theories of Substance in Leibniz: Critical Notice of Daniel Garber, Leibniz: Body, Substance, Monad." Philosophical Review 120(2): 285-320.

----. 2005. "Leibniz on Precise Shapes and the Corporeal World." In Leibniz: Nature and Freedom, ed. D. Rutherford and J. Cover, 69-94. New York: Oxford University Press.

----. 2003. "The Interval of Motion in Leibniz's Pacidius Pbilalethi." Noûs 37(3): 371-416.

----. 1998. "Leibniz on Mathematics and the Actually Infinite Division of Matter." Philosophical Review 107(1): 49-96.

Marshall, Douglas. 2011. "Leibniz: Geometry, Physics and Idealism." The Leibniz Review 21: 9-32.

McDonough, Jeffrey K. 2014. "Leibniz's Philosophy of Physics," The Stanford Encyclopedia of Philosophy (Spring 2014 Edition), ed. Edward N. Zalta. plato.stanford.edu/archives/spr2014/entries/leibniz-physics/.

----. 2013. "Leibniz's Conciliatory Account of Substance," Philosopher's Imprint 13(6).

----. forthcoming-a. "Leibniz's Optics." In The Oxford Handbook of Leibniz, ed. Maria Rosa Antognazza. Oxford: Oxford University Press. 
----. forthcoming-b. "Leibniz, Spinoza and an Alleged Dilemma for Rationalists,” Ergo.

----. 2010. "Leibniz's Optics and Contingency in Nature." Perspectives on Science 18(4): 432-55.

More, Henry. 1659. The Immortality of the Soul. London: J. Flesher.

Newton, Isaac. 2004. Philosophical Writings, ed. Andrew Janiak. Cambridge: Cambridge University Press.

Ockham, William. 1967-1989. Opera philosophica et theological. St. Bonaventure: Franciscan Institute. Reference is to volume and page.

Olivi, Peter John. 1922. Quaestiones in secundum librum Sententiarum, ed. B. Jansen. Quaracchi: Collegium S. Bonaventurae.

Pasnau, Robert. 2011. Metaphysical Themes 1274-1671. New York: Oxford University Press.

Phemister, Pauline. 1999. "Leibniz and the Elements of Compound Bodies." British Journal for the History of Philosopby 7(1): 57-78.

----. 2005. Leibniz and the Natural World: Activity, Passivity, and Corporeal Substances in Leibniz's Pbilosophy. Dordrecht: Springer.

Plato. 1989. The Collected Dialogues of Plato, ed. Edith Hamilton and Huntington Cairns. Princeton, NJ: Princeton University Press.

Rescher, Nicholas. 1986. Leibniæ: An Introduction to His Pbilosophy. Lanham, MD: University Press of America.

De Risi, Vincenzo. 2007. Geometry and Monadology: Leibniz's Analysis Situs and Philosophy of Space. Basel: Birkhäuser.

Rosen, Gideon. 2010. "Metaphysical Dependence: Grounding and Reduction.” In Modality: Metaphysics, Logic, and Epistemology, ed. R. Hale and A. Hoffman, 109-36. New York: Oxford University Press. 
Russell, Bertrand. 1937. A Critical Exposition of the Philosophy of Leibniz, 2nd edition. London: George Allen and Unwin.

Rutherford, Donald. 1990. "Phenomenalism and the Reality of Body in Leibniz’s Later Philosophy.” Studia Leibnitiana 22: 11-28.

---- 1995. Leibniz and the Rational Order of Nature. Cambridge: Cambridge University Press.

----. 2004. "Idealism Declined: Leibniz and Christian Wolff." In Leibniz and

his Correspondents, ed. Paul Lodge, 213-37. Cambridge: Cambridge University Press.

---. 2008. "Leibniz as Idealist." Oxford Studies in Early Modern Philosophy 3: $141-90$.

Schaffer, Jonathan. 2009. “On What Grounds What.” In Metametaphysics: New Essays on the Foundations of Ontology, ed. D. Chalmers, D. Manley, and R. Wasserman, 347-83. Oxford: Oxford University Press.

Suárez, Francisco. 1965. Disputationes metaphysicae. Paris: Vivès (1866); repr. Hildesheim: Olms.

Truesdell, C. 1957. The Rational Mechanics of Flexible or Elastic Bodies, 16381788. In Leonhardi Euleri, Opera Omnia, series 2, vol. 11, part 2, ed. Joachim Otto Fleckenstein, 11-416. Turici: Orell Füssli.

Wolff, Christian. 1964. Cosmologia Generalis. In Gesammelte Werke, Abteilung II, Band 4. Hildesheim: Georg Olms Verlagsbuchhandlung.

Winterbourne, A. T. 1982. "On the Metaphysics of Leibnizian Space and Time." Studies in History and Pbilosophy of Science 13: 201-14.

Wilson, Margaret. 2009. "The Phenomenalisms of Leibniz and Berkeley." In Ideas and Mechanism, 306-22. Princeton: Princeton University Press.

Wilson, Mark. 2010. "From the Bending of Beams to the Problem of Free Will." A Priori 4. Citation is to section number. 